\title{
How Different Stressors Affect Quality of Life: An Application of Multilevel Latent Class Analysis on a Large Sample of Industrial Employees
}

This article was published in the following Dove Press journal: Risk Management and Healthcare Policy

\author{
Roqayeh Parsaei (1D) \\ Hamidreza Roohafza ${ }^{2}$ \\ Awat Feizi ${ }^{3}$ \\ Masoumeh Sadeghi ${ }^{2}$ \\ Nizal Sarrafzadegan (D) ${ }^{4}$ \\ 'Department of Biostatistics and \\ Epidemiology, School of Health, and \\ Student Research Committee, School of \\ Health, Isfahan University of Medical \\ Sciences, Isfahan, Iran; ${ }^{2}$ Cardiac \\ Rehabilitation Research Center, \\ Cardiovascular Research Institute, Isfahan \\ University of Medical Sciences, Isfahan, \\ Iran; ${ }^{3}$ Department of Biostatistics and \\ Epidemiology, School of Health, and \\ Cardiac Rehabilitation Research Center, \\ Cardiovascular Research Center, \\ Cardiovascular Research Institute Isfahan \\ University of Medical Sciences, Isfahan, \\ Iran; ${ }^{4}$ Isfahan Cardiovascular Research \\ Center, Cardiovascular Research \\ Institute, Isfahan University of Medical \\ Sciences, Isfahan, Iran
}

Background: Quality of life (QoL) indicates individual's perception of the physical, psychological and social aspects of health. The association between QoL and all stressful life events' dimensions has not been investigated among industrial employees.

Purpose: The present study aimed to investigate the association between stressful life events and QoL in a large sample of Iranian industrial employees.

Material and Methods: In a cross-sectional study, 3063 manufacturing employees in Isfahan, Iran, were recruited. QoL was measured with the Euro-QoL five dimension questionnaire (EQ-5D). Stressful life events were assessed by an Iranian validated stressful life event questionnaire (SLE). Multilevel latent class regression was employed for classifying participants based on QoL and for determining its association with stressful life events.

Results: Two classes of employees, ie, low (comprised 20\% of participants) and high QoL $(80 \%)$, were identified. From 11 dimensions of stressful life events two major domains, socioeconomic and personal stressor profiles, were identified. Multilevel latent class regression results showed that the higher scores of social (OR: 1.14, 95\% $\mathrm{CI}: 1.12-1.16$ ) and personal (OR: 2.36, 95\%CI: 1.87-2.98) stressor domains were significantly associated with increased risk of being in the poor QoL class. Among personal and socioeconomic stressors, health concerns and daily life dimensions had higher significant association with poor QoL.

Conclusion: Results of our study indicated that life stressors have negative impacts on QoL of employees. Personal stressors showed higher negative impact than socioeconomic on QoL. Managing the stressors can play an effective role in improving the QoL of employees, their physical and mental health, and indirectly enhances the organizational performance and job productivity.

Keywords: quality of life, stressful life events, multilevel latent class analysis

\section{Introduction}

Quality of life (QoL) is one of the most important outcomes in health-care programs. $^{1,2}$ QoL is an individual, multidimensional and latent concept that involves both objective and subjective factors, reflecting the physical, mental, and social health of a person. ${ }^{3-5}$ The World Health Organization also defines QoL as: “individuals' perceptions of their position in life in the context of the culture and value systems in which they live and in relation to their goals, expectations, standards and concerns" 6

QoL influences the quality of work life and work characteristics such as productivity. $^{7-11}$ QoL has been found to be negatively associated with stress. ${ }^{12,13}$
Correspondence: Awat Feizi Isfahan University of Medical Sciences, P. O. Box 319, Hezarjarib Ave, Isfahan, Iran Tel +983137923250

Email awat_feiz@hlth.mui.ac.ir
Risk Management and Healthcare Policy 2020:13 |26|-1270

bmit your manuscrip

DovePres: in $\square$ 
Increased stress levels are related to decreased job performance, higher medical costs, and impaired QoL. ${ }^{14,15}$ A number of studies have reported significant association between psychological stressors and poor physical and mental health. ${ }^{16,17}$ Furthermore, stressful life events are inversely related to QoL and well-being. ${ }^{18-20}$ Stressful life events were defined by the occurrence of both positive and negative situations in an individual's life that lead to significant changes in usual activities. ${ }^{18}$

The body's response to stress is attributed to the activity of several axes, such as the hypothalamic-pituitary-adrenal (HPA) axis and sympathetic adrenomedullary circuits. Stressful life events through the HPA axis can affect the function of neuroendocrine and immune systems, physical and psychological well-being. ${ }^{21-23}$ Long-term stress by changing many physiological systems, such as metabolic and inflammatory pathways and immunological defense systems in the body leads to function and cell senescence impairment. $^{24}$

Stressful life events have been identified as a risk factor for a variety of physical and mental illnesses such as cardiovascular disease, cancer, metabolic syndrome, and depression. ${ }^{25-28}$

Stressful life events can also lead to changes in jobrelated behaviors such as reduced job involvement, impaired performance effectiveness, and reduced job satisfaction and eventually absenteeism, tardiness and turnover. ${ }^{29}$

Numerous studies are available on the relation between QoL and stressful life events across different populations such as diseases-specific populations ${ }^{30-32}$ and older adults ${ }^{20,33}$ and less attention has been paid to evaluate it among the workforce or general population. ${ }^{5,34}$

Furthermore, in many studies among the workforce population, the association between QoL and job stress has been widely studied but other stressors have been neglected. ${ }^{35-38}$ However, individuals are exposed to multiple stressors which may affect their QoL. Understanding the relationships between QoL and stressors as well as job stress may help in planning interventions to reduce negative effects of stressors and consequently improve QOL among the workforce.

Moreover, most of the previous studies on the determinants of QoL have applied simple statistical analysis and the subscale scores were combined to obtain an overall, or total QoL score as a single measure. However, QoL is a multidimensional concept with distinct domains. To make statistical analysis about QoL as a multidimensional and latent variable, an advanced statistical procedure is required that can perform a comprehensive assessment of QoL in the study participants according to all five dimensions of QoL.

Latent class analysis (LCA) ${ }^{39}$ as an advanced statistical method that provides such a comprehensive evaluation of QoL by classifying the subjects into mutually exclusive and exhaustive and homogenous groups. In the current study, an extended version of LCA was used to assess QoL while simultaneously addressing dependencies due to multilevel structure of study population (ie, employees as lower level units nested in job categories as a higher level).

To our knowledge, no large-scale study has focused on the relationship between stressors and QoL among industrial employees in Iran.

Therefore, the objectives of the present study were: (1) to classify the participants as well as the job categories based on QoL; and (2) to evaluate the association of stressful life events with QoL using multilevel latent class regression (MLLCR) analysis. This method provides a comprehensive feature about QoL through classifying employees objectively based on all domains of QoL and simultaneously enable us to evaluate the association of stressful life events with QoL classes in the presence of various confounders including demographic, lifestyle, and job-related variables.

\section{Materials and Methods Study Design and Participants}

This cross-sectional study was conducted among full-time employees and contractual workers of the Esfahan Steel Company (workforce of 16,000). The sample size was determined based on an epidemiological survey of chronic diseases in manufacturing employees by Roohafza et al $(\mathrm{ESCOME})^{40}$ carried out to estimate the prevalence of psychological disorders (depression and anxiety) among the workforce. The sample size was estimated to be 3500 by considering $0.1,0.05$, and 0.01 as prevalence of psychological disorders, type one error rate, and sampling error rate, respectively.

Three thousand and sixty-three volunteers returned complete questionnaires (response rate: 0.87) and were included in the statistical analysis. The inclusion criterion was work experience for at least one year and being willing and agreeing to participate in the study. Volunteers who did not answer more than $10 \%$ of the questionnaire were excluded from the analysis. 
We applied multistage cluster sampling, in which clusters were the main seven departments and their sections, stratified by job categories. Sample sizes in the clusters and strata were proportional to the size of respective departments. Due to a low number of women workers $(n=800)$, we relied on convenience sampling to recruit women volunteers $(\mathrm{n}=260)$.

Demographic data were gathered through self-administered questionnaires at the company premises with the help of study coordinators, who also monitored questionnaire administration over the six months of data gathering. The data were quality checked for inclusion and exclusion criteria as they were entered in the computer for statistical analysis. The study design and its implementation has been presented elsewhere in more detail. ${ }^{40,41}$

Employees are mainly divided into two categories including white-collar and blue-collar employees. Employees in managerial and supervisory positions were considered as high-level white-collar employees (4.9\%) and office employees were considered as low-level white-collar employees (15.2\%). Blue-collar employees were also classified as high-level (skilled workers) (16.4\%) and low-level (semi-skilled and nonprofessional workers) $(63.5 \%){ }^{40}$

Employees based on their job groups, employee rank, and work conditions have been divided into 71 job categories, such as manager, technical supervisor, nontechnical supervisor, first class electrician repairman, second class electric repairman, first class mechanical repairman, second class mechanical repairman, first-class engineer, second class-engineer, senior engineer, firefighter, welder, driver, etc.

All participants were informed about the study protocol and signed informed consent. The Medical Research Ethics Committee of the Isfahan University of Medical Sciences approved the study protocol (project numbers \#87115 and \#395482). This study was conducted in accordance with the Declaration of Helsinki. ${ }^{42}$

\section{Study Instruments and Assessment of Variables Quality of Life}

A standardized and generic form of the Euro QoL-five dimensions (EQ-5D-3L) ${ }^{43,44}$ was used for assessing QoL. This self-report instrument comprises two parts of the selfclassifier (descriptive system) and the visual analog scale (VAS).
The EQ-VAS was considered as a single value for assessing of overall health status. This is a VAS, ranging from 0 (worst imaginable health) to 100 (best imaginable health). Respondents by marking the scale with a single vertical mark, rate their current health status. EQ-5D self-classifier describes health state of subjects in five domains: mobility, self-care care, normal activities, pain/discomfort, anxiety and depression. Each domain consists of three levels: no problem (1), some problems (2), severe problems (3). We combined the last two categories into a single category in LCA due to poor response rate in last category. Higher EQ-5D scores represent worse health status. The Iranian validated version of EQ-5D has been used in the current study and it has shown good reliability and validity. ${ }^{45,46} \mathrm{We}$ evaluated the internal reliability of the questionnaire in a pilot sample of 300 participants in current study and Cronbach alpha was 0.51 . The EQ-5D score was able to differentiate patients according to the severity of the disease based on the EQ-5D VAS $(P<0.0001)$. The ICC for EQ-5D and EQ-5D VAS were 0.753 and 0.896 , respectively. The correlation of total score of the EQ-5D questionnaire with the total scores of SF-36 was $(\mathrm{r}=0.445, P<0.05)$ and dimensions of EQ-5D questionnaire with counterpart dimensions from SF-36 questionnaire were $(r=0.37-0.45)$ indicating a moderate correlation. ${ }^{47}$

\section{Stressful Life Events}

The number and intensity of experienced life stressors were measured by the Stressful Life Events (SLE) questionnaire. ${ }^{48}$ Participants were asked about the occurrence of stressors within the past six months. The SLE is a 46-item self-administered scale which consists of eleven dimensions, including home life (measured with seven items), financial problems (five items), social relations (four items), personal conflicts (five items), job conflicts (four items), educational concerns (four items), job security (five items), loss and separation (four items), sexual life (four items), daily life (two items), and health concerns (two items). The items are rated on a six-point Likert scale (0: never, 1: very mild, 2: mild, 3: moderate, 4: severe, 5: very severe) and the higher score indicates higher stress level. Internal consistency of the SLE questionnaire was $0.92 .{ }^{48}$

\section{Assessment of Other Variables}

Variables that were considered as potential confounders included demographics, age (years), gender (male/female), marital status (married/single), education ( $0-5$ years/6-12 years/over 12 years), lifestyle variables, sleep duration (hours) and physical activity (hours per week), BMI 
(weight $\mathrm{kg} /$ height $\mathrm{m}^{2}$ ), job-related variables, job stress (effort-reward imbalance), and second job (yes/no). Physical activity was evaluated with the International Physical Activity Questionnaire (IPAQ), which included 11 questions. The internal reliability of this questionnaire was reported as good by Moghaddam et $\mathrm{al}^{49}$ based on Cronbach's alpha of 0.7 and Spearman-Brown correlation coefficient of 0.9 .

\section{Statistical Analysis}

Two-level LCA $^{50-52}$ (employees as level one and job categories level two units) was employed to identify homogeneous latent classes of employee according to the their responses to five indicators of QoL. Multilevel LCA is an extension of traditional LCA that handles situations where there is a multilevel construct. In our study, employees (level one) are nested within job categories (level two).

The two-level latent class model not only classifies the employees but also the job categories based on the distribution of QoL of employees nested in job categories. The modeling process consists of the following steps: in the first step, with ignoring the nesting structure of data, LCA was used to classify individuals based on their response to the five items of the EQ-5D. To determine the appropriate number of classes at the employee-level, we started by fitting a one-class model and sequentially increased the number of classes until to yield the best fit. Bayesian Information Criterion ${ }^{53}$ was used to select the best-fitting model. In addition, interpretability of the identified classes was also considered.

In the next step, two-level latent class model was estimated to take (the clustered nature of the data) into account the multilevel structure of our data. A two-level model with two classes at level one and two classes at the second level was selected as the best fit.

Finally, we used the MLLCR for evaluating the predictors of QoL. The proposed predictors of QoL in current study were stressors. For evaluating their association with QoL, at first, we used exploratory factor analysis on eleven domains of life stressors. Two factors were extracted and labeled as "personal stressors" and "socioeconomic stressors" and these domains were used as latent predictors of QoL of employees. The association of two extracted stressor domains with quality of life in the structure of MLLCR was quantified as OR and $95 \% \mathrm{CI}$ for OR.

We adjusted the association of those potential confounding variables that were statistically significant at $P<0.1$ in univariate analyses.
Continuous and categorical variables were represented as mean (SD) and number (percentage) respectively. Independent samples $t$-test/Mann-Whitney $U$-test and chi-squared test were used for comparing continuous and categorical variables between studied groups, respectively. MLLCR was fitted in Mplus statistical software (Muthén and Muthén, Los Angeles, CA, USA; version 8). ${ }^{54}$

\section{Results}

The current study consists of 3063 participants aged 21-64 mean (SD): 36.73 (7.30) years. Most of the participants were male (91.5\%), 90\% married and $29.4 \%$ of the employees had a university education.

Table 1 presents the two classes at the employees' level based on five dimensions of QoL identified by LCA. The first class is characterized by higher probabilities of expressing "no problem" for all items of QoL. Accordingly, this class was labeled as high QoL (consisted of $80 \%$ participants). The second class is characterized by higher probabilities of expressing "some/severe problems" for items of mobility, pain/discomfort and anxiety/depression. Accordingly, we named this class as low QoL (consisted of 20\% participants).

Using exploratory factor analysis, two factors were identified from eleven life stressors (Table 2). Financial problems, social relations, personal conflicts, job conflicts, educational concerns, job security and daily life were loaded more on first factor. Accordingly, this factor was labeled as "socioeconomic stressors". Home life, loss and separation, sexual life and health concerns stressors were highly loaded on the second factor. Therefore, this factor was labeled as "personal stressors". 41,55

Differences in demographic, life style and job-related variables between two extracted classes of QoL are shown in Table 3. These results indicated that the subjects who were classified as high QoL, were more likely to be younger, male, and have lower BMI and higher sleep duration than those in the low QoL class.

Differences between the two classes in terms of the scores of stressful life events domains and two extracted socioeconomic and personal stressor dimensions are reported in Table 4. Compared with those people in the high QoL class, individuals in the low QoL class had higher mean stress scores in all eleven stressor domains as well as socioeconomic and personal stressors (Table 4).

Figure 1 shows the two-level latent class model with two classes at level one (employees) and two classes in the second level (job categories) and the distribution of employee's classes in terms of QoL at the classes of job 
Table I Latent Classes of QoL Identified by Latent Class Analysis

\begin{tabular}{|c|c|c|}
\hline & \multicolumn{2}{|c|}{$\begin{array}{l}\text { Class-specific } \\
\text { Response } \\
\text { Patterns of } \\
\text { Participants to } \\
\text { EQ-5D Items }\end{array}$} \\
\hline Levels of Quality of Life & $\begin{array}{l}\text { Low } \\
\text { QoL }\end{array}$ & $\begin{array}{l}\text { High } \\
\text { QoL }\end{array}$ \\
\hline Class size & $\begin{array}{l}621 \\
(0.20)\end{array}$ & $\begin{array}{l}2442 \\
(0.80)\end{array}$ \\
\hline $\begin{array}{l}\text { Items of EQ-5D questionnaire } \\
\text { Mobility } \\
\text { I have no problems in walking about } \\
\text { I have some problems in walking about/l am } \\
\text { confined to bed }\end{array}$ & $\begin{array}{l}0.69 \\
0.31\end{array}$ & $\begin{array}{l}0.99 \\
0.01\end{array}$ \\
\hline $\begin{array}{l}\text { Self-care } \\
\text { I have no problems with self-care } \\
\text { I have some problems washing or dressing } \\
\text { myself/l am unable to wash or dress myself }\end{array}$ & $\begin{array}{l}0.99 \\
0.01\end{array}$ & $\begin{array}{l}1.00 \\
0.00\end{array}$ \\
\hline $\begin{array}{l}\text { Usual activities (eg work, study, housework, } \\
\text { family or leisure activities) } \\
\text { I have no problems with performing my usual } \\
\text { activities } \\
\text { I have some problems with performing my } \\
\text { usual activities/l am unable to perform my usual } \\
\text { activities }\end{array}$ & $\begin{array}{l}0.94 \\
0.06\end{array}$ & $\begin{array}{l}1.00 \\
0.00\end{array}$ \\
\hline $\begin{array}{l}\text { Pain/discomfort } \\
\text { I have no pain or discomfort } \\
\text { I have moderate pain or discomfort/l have } \\
\text { extreme pain or discomfort }\end{array}$ & $\begin{array}{l}0.13 \\
0.87\end{array}$ & $\begin{array}{l}0.94 \\
0.06\end{array}$ \\
\hline $\begin{array}{l}\text { Anxiety/depression } \\
\text { I am not anxious or depressed } \\
\text { I am moderately anxious or depressed/I am } \\
\text { extremely anxious or depressed }\end{array}$ & $\begin{array}{l}0.48 \\
0.52\end{array}$ & $\begin{array}{l}0.89 \\
0.11\end{array}$ \\
\hline
\end{tabular}

Note: Data are presented as percentage.

Abbreviation: QoL, quality of life.

categories. "Job categories with low QoL" consists of a higher percentage of employees with low QoL (27.2\%) whereas a larger percentage of "job categories with high QoL" contains employees with high QoL (84.5\%).

The crude and adjusted ORs (95\%CI for OR) for the association of socioeconomic and personal stressors and all domains of stressful life events with QoL in the presence of demographic, lifestyle and job-related confounding variables are presented in Table 5. Higher scores of socioeconomic (OR: 1.15, 95\%CI: 1.13-1.17) and personal stressors (OR: 2.56, 95\%CI: 2.02-3.24) are associated with increased
Table 2 Factor Loadings of Two Extracted Factors from Stressful Life Events

\begin{tabular}{|l|l|l|}
\hline Stressful Life Events & $\begin{array}{l}\text { Socioeconomic } \\
\text { Stressors }\end{array}$ & $\begin{array}{l}\text { Personal } \\
\text { Stressors }\end{array}$ \\
\hline Financial problems & 0.80 & \\
Social relation & 0.74 & \\
Personal conflicts & 0.67 & \\
Job conflicts & 0.70 & \\
Educational concerns & 0.40 & \\
Job security & 0.81 & \\
Daily life & 0.58 & 0.51 \\
Home life & & 0.62 \\
Loss and separation & & 0.53 \\
Sexual life & & 0.61 \\
Health concerns & & \\
\hline
\end{tabular}

Note: For each life stressor, the highest factor loading has been reported.

Table 3 Demographic Characteristics, Lifestyle, Job-related Variables of Participants in Two Classes of QoL

\begin{tabular}{|l|l|l|l|}
\hline \multirow{2}{*}{ Variables } & \multicolumn{2}{|l|}{ Levels of QoL (QoL Class) } & \multirow{2}{*}{ P-value } \\
\cline { 2 - 3 } & Low QoL & High QoL & \\
\hline Sex & & & \\
Male & $547(88.1)$ & $2256(92.4)$ & \multirow{2}{*}{0.001} \\
\hline Female & $74(11.9)$ & $186(7.6)$ & \\
Marital status & & & \\
Sarried & $568(91.5)$ & $2190(89.7)$ & 0.18 \\
\hline Education level & $53(8.5)$ & $252(10.3)$ & \\
0-5 years & & & \\
6-12 & $41(6.6)$ & $214(8.8)$ & 0.19 \\
$>12$ & $389(62.6)$ & $1519(62.2)$ & \\
\hline Shift work & $191(30.8)$ & $709(29)$ & \\
Daily (daily shift) & & & \\
Shift (rotational shift work) & $316(50.9)$ & $1064(43.6)$ & 0.001 \\
\hline Second job & $305(49.1)$ & $1378(56.4)$ & \\
Yes & & & \\
Household size & $54(8.7)$ & $231(9.5)$ & 0.56 \\
Age (years) & $3.74 \pm 1.12$ & $3.58 \pm 1.10$ & 0.001 \\
BMI (kg/m²) & $38.48 \pm 7.22$ & $36.26 \pm 7.26$ & $<0.001$ \\
Physical activity (h/week) & $26.09 \pm 4.11$ & $25.46 \pm 3.70$ & $<0.001$ \\
Sleep duration (h) & $9.20 \pm 14.51$ & $9.97 \pm 15.55$ & 0.26 \\
\hline Not & $6.91 \pm 1.22$ & $7.16 \pm 1.15$ & $<0.001$ \\
\hline
\end{tabular}

Notes: $P$-values resulted from two independent samples $t$-test or Mann-Whitney $U$-test and chi-squared test for continues and categorical variables, respectively. Values are mean (SD) and frequency (percentage) for continuous and categorical variables, respectively.

Abbreviations: QoL, quality of life; BMI, body mass index.

risk of being in the poor QoL class in crude model. In this model an increase of one unit in socioeconomic or personal stressors' score, increases the risk of being in the low QoL class by 1.15 and 2.56 times, respectively. 
Table 4 Mean Scores of Stressful Life Events Across Two Classes of QoL

\begin{tabular}{|l|l|l|l|}
\hline \multirow{2}{*}{ Stressful Life Events } & \multicolumn{2}{|l|}{ Levels of QoL } & \multirow{2}{*}{ P-value } \\
\cline { 2 - 3 } & Low QoL & High QoL & \\
\hline Socioeconomic stressors & $5.15 \pm 3.04$ & $3.28 \pm 2.58$ & $<0.001$ \\
Financial problems & $9.87 \pm 6.80$ & $7.09 \pm 6.17$ & $<0.001$ \\
Social relations & $6.07 \pm 5.04$ & $3.58 \pm 4.28$ & $<0.001$ \\
Personal conflicts & $3.89 \pm 4.87$ & $3.13 \pm 1.73$ & $<0.001$ \\
Job conflicts & $4.18 \pm 5.42$ & $3.73 \pm 3.48$ & $<0.001$ \\
Educational concerns & $2.95 \pm 1.81$ & $2.20 \pm 1.02$ & $<0.001$ \\
Job security & $3.94 \pm 5.56$ & $3.79 \pm 3.99$ & $<0.001$ \\
Daily life & $2.58 \pm 3.42$ & $2.07 \pm 2.01$ & $<0.001$ \\
Personal stressors & $1.67 \pm 1.51$ & $0.73 \pm 1.01$ & $<0.001$ \\
Home life & $2.27 \pm 3.39$ & $0.86 \pm 2.09$ & $<0.001$ \\
Loss and separation & $2.81 \pm 2.11$ & $2.17 \pm 1.27$ & $<0.001$ \\
Sexual life & $1.56 \pm 0.50$ & $1.23 \pm 0.32$ & 0.008 \\
Health concerns & $2.16 \pm 1.80$ & $1.27 \pm 0.46$ & $<0.001$ \\
\hline
\end{tabular}

Note: $P$-values resulted from two independent sample $t$-test or Mann-Whitney $U$ test.

The association of socioeconomic (OR: 1.12, 95\%CI: 1.12-1.16) and personal stressors scores (OR: 2.48, 95\% CI: 1.96-3.14) with low QoL remained statistically significant after adjustment for demographic variables including age, sex, and household size. A one-unit increase in socioeconomic stressors' score was associated with $12 \%$ increase in odds of being in low QoL class and a one-unit increase in personal stressors' score was associated with a 2.48 times increase in risk of being in the low QoL class.

These associations, remained significant even after adjustment for the association of other confounders including BMI, sleep duration and shift work. In the fully adjusted model, it was observed that one unit increase in socioeconomic stressors' score was significantly associated with 14\% increased risk for being in the low QoL class (OR:1.14, 95\%CI: 1.12-1.16) and one-unit increase in personal stressors score, enhances the risk of being in the low QoL class by 2.36 times (OR: $2.36,95 \% \mathrm{CI}$ : 1.87-2.98).

All dimensions of stressful life events were found to be significantly associated with increased risk of belonging to the low QoL class in both crude and adjusted models. Health concerns, daily life, and home life had the strongest association with low QoL which resulted in ORs of 1.40, 1.23 and 1.17 , respectively.

\section{Discussion}

This cross-sectional study examined the association between stressful life events and QoL using MLLCR analysis among 3063 Iranian industrial employees. Two classes of employees, as lower-level units, and two classes of job categories, as higher-level units, were identified according to QoL indicators. These classes were labeled as high, low or poor QoL. Poor QoL, was significantly associated with higher scores of social and personal stressor profiles extracted from 11 dimensions of stressful life events. However, the strength of the associations was markedly higher for personal stressors than socioeconomic stressors. Higher scores of all dimensions of stressful life events were significantly associated with increased risk of low QoL. Among them health concerns, daily life and home life had the greatest associations with low QoL.

To the best of our knowledge, the current study is the first one that was conducted on employees and classified individuals by considering all aspects of QoL and constructed two parsimonious and comprehensive measures

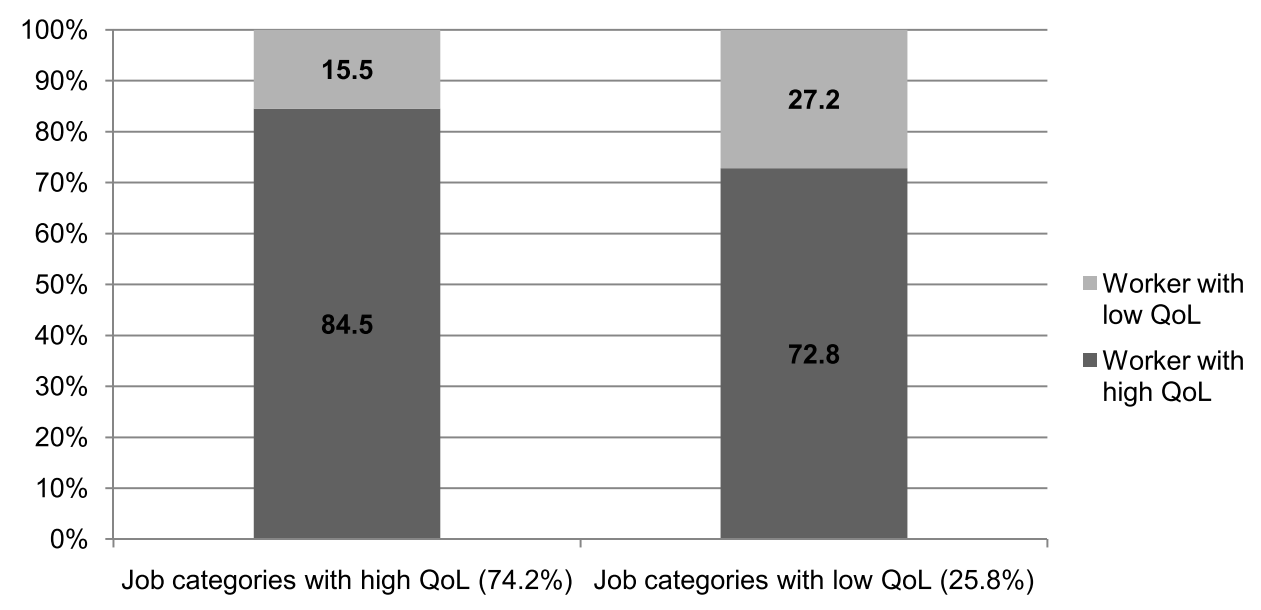

Figure I Distribution of level-one latent classes ( $n=3063$ employees) within level-two latent classes ( $n=7 \mid$ job categories). 
Table 5 Crude and Multivariable Adjusted Odds Ratio (OR) and 95\% Confidence Interval (95\%Cl for OR) of the Association of Stressful Life Events Scores and QoL

\begin{tabular}{|c|c|c|c|c|c|c|}
\hline \multirow[t]{2}{*}{ Stressful Life Events } & \multicolumn{2}{|l|}{ Crude Model } & \multicolumn{2}{|l|}{ Model I ${ }^{\mathbf{a}}$} & \multicolumn{2}{|l|}{ Model $2^{b}$} \\
\hline & $\begin{array}{l}\text { Odds Ratio (OR) } \\
\text { (95\%Cl OR) }\end{array}$ & P-value & $\begin{array}{l}\text { Odds Ratio (OR) } \\
\text { (95\%Cl OR) }\end{array}$ & P-value & $\begin{array}{l}\text { Odds Ratio (OR) } \\
\text { (95\%Cl OR) }\end{array}$ & P-value \\
\hline Socioeconomic stressors & $1.15(1.13-1.17)$ & $<0.001$ & $1.14(1.12-1.16)$ & $<0.00$ I & $1.14(1.12-1.16)$ & $<0.001$ \\
\hline Financial problems & $1.05(1.04-1.06)$ & $<0.001$ & $1.05(1.03-1.07)$ & $<0.00$ I & $1.05(1.03-1.07)$ & $<0.001$ \\
\hline Social relations & $1.12(1.09-1.14)$ & $<0.001$ & $1.12(1.09-1.14)$ & $<0.001$ & $1.12(1.09-1.14)$ & $<0.001$ \\
\hline Personal conflicts & $1.13(1.11-1.15)$ & $<0.001$ & $1.12(1.09-1.14)$ & $<0.00$ I & $1.12(1.09-1.14)$ & $<0.001$ \\
\hline Job conflicts & $1.10(1.08-1.13)$ & $<0.001$ & $1.11(1.08-1.13)$ & $<0.00$ I & $1.11(1.08-1.13)$ & $<0.001$ \\
\hline Educational concerns & $1.08(1.06-1.10)$ & $<0.001$ & $1.07(1.05-1.09)$ & $<0.00$ I & $1.07(1.05-1.09)$ & $<0.001$ \\
\hline Job security & $1.07(1.05-1.09)$ & $<0.001$ & $1.08(1.06-1.10)$ & $<0.00$ I & $1.08(1.06-1.10)$ & $<0.001$ \\
\hline Daily life & $1.23(1.19-1.28)$ & $<0.001$ & $1.23(1.19-1.28)$ & $<0.00$ I & $1.23(1.19-1.28)$ & $<0.001$ \\
\hline Personal stressors & $2.56(2.02-3.24)$ & $<0.001$ & $2.48(1.96-3.14)$ & $<0.00$ I & $2.36(1.87-2.98)$ & $<0.001$ \\
\hline Home life & $1.19(1.14-1.23)$ & $<0.001$ & $1.22(1.13-1.23)$ & $<0.00 \mathrm{I}$ & $1.17(1.13-1.22)$ & $<0.001$ \\
\hline Loss and separation & $1.09(1.07-1.12)$ & $<0.001$ & $1.07(1.05-1.09)$ & $<0.00$ I & $1.07(1.05-1.09)$ & $<0.001$ \\
\hline Sexual life & $1.07(1.03-1.12)$ & $<0.001$ & $1.07(1.03-1.12)$ & $<0.00$ I & $1.07(1.03-1.12)$ & $<0.001$ \\
\hline Health concerns & $1.43(1.35-1.52)$ & $<0.001$ & $1.42(\mid .34-1.5 \mathrm{I})$ & $<0.00$ I & $1.40(1.32-1.49)$ & $<0.001$ \\
\hline
\end{tabular}

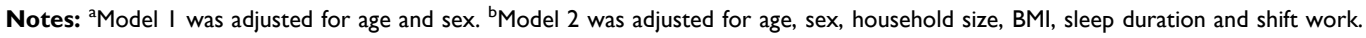

Abbreviation: QoL, quality of life .

from all dimensions of stressful life events and evaluated their association with QoL using MLLCR analysis.

We found that the social and personal stressor profiles were associated with low QOL. These findings are in line with some previous studies that have focused on cumulative stressful life events in relation to QoL and well-being. ${ }^{5,18,30,31,33}$ In a population-based study of individuals with chronic obstructive pulmonary disease (COPD) in Singapore, higher stressful life event scores were associated with lower physical and mental health scores. ${ }^{30}$ The study of Staniute et al on 560 coronary artery disease patients in Lithuania indicated negative relationship between stressful life events and QoL. ${ }^{31}$ In a study among adults aged 60 years and older in Bhutan, stressful life events during childhood and adulthood were negatively associated with overall QoL. ${ }^{33}$

Our findings are consistent with some parts of previously reported studies, which have supported a negative association between stressful life events and QoL. ${ }^{34,56}$ Damush et al, in their study on college students, have reported a statistically significant relationship between autonomous life events, distressful life events, family/parental life events, sexual life events and poor QoL. ${ }^{56}$ Similarly, in a study among Indian undergraduate medical and dental students, stress related to academics, selfexpectations, relationships and living conditions were associated with decreased QoL including physical, psychological, social, and environmental dimensions and stress related to health and value conflict leads to decrease in physical and social components of QoL. ${ }^{57}$

Our findings are inconsistent with some previous results. ${ }^{34,56,58}$ Villalonga-Olives et al, in a study among Spanish adolescents and youths, did not find significant association between family and extra family events and desirable events and QoL. ${ }^{58}$ Damush et al, in their study on college students, did not find significant relationship between accident/illness, deviance and relocation events with QoL. ${ }^{56}$ Cleland et al, in a longitudinal study, found that new job/promotion and parenthood events positively impact on physical QoL. ${ }^{34}$

There are several possible reasons for this difference. (1) One possibility may be due to population difference. (2) Impact of stressful life events on wellbeing and QoL may vary depending on the appraisal of stressors ${ }^{34}$ and compassionate skills $^{59}$ by different individuals. (3) Differences in cultural characteristics can also be a factor that may change the impact of events on QoL among individuals. ${ }^{60}$

The possible mechanism that underlies the relationship between stressful life events and physical QoL includes neuroendocrine responses. Stressful life events can make people susceptible and vulnerable to chronic and acute diseases through changes in immune competence that are mediated by the neuroendocrine system. Stressful life 
events may be associated with QoL indirectly through impairing their psychological health. ${ }^{61}$ Some psychological responses to stress include changes in cognitive functions such as limitation of perceptions, reduced ability to concentrate, change in emotional responses such as anxiety and depression. ${ }^{62}$ Potential mediators, including elevated levels of cortisol and neurotoxicity might underlie the impact of stressful life events on physical and mental health. ${ }^{20}$ Longterm stress can lead to dysregulation of the allostatic system by altering physiological processes within the body, and thus contribute to health morbidities ${ }^{24,63}$ and consequently, QoL. Another possible pathway for explaining the stress effects on health and finally QoL, is directed through behavioral changes such as increased smoking, decreased exercise and sleep duration and quality. ${ }^{64,65}$

In the present study, it was found also that personal stressors were more strongly related to poor QoL than socioeconomic stressors. This result is in agreement with Holmes and Rahe Stress Scale in which death of a spouse, divorce, marital separation, death of close family member and personal injury or illness ranked as the highest stressors. ${ }^{66}$

This finding emphasizes that adequate supports are important for people with exposure to life events such as health concerns and bereavement. ${ }^{34}$

Although in current study, personal stressors had a strong association with QoL but sexual life dimension had the lowest strength. This result may be attributed to the fact that some people probably have not correctly answered to the questions in the area of this type of stressor because of cultural constraints and limitations about declaration of sexual issues in public settings.

\section{Study Strengths and Limitations}

The major strength of the present research is the use of an advanced statistical model that provides a comprehensive evaluation of both life stressors and QoL and their association. Other strengths of the current study include the large sample of industrial employees and that the estimated association between life stressors and QoL have been adjusted for many potential confounding variables. The present study has several limitations that it is necessary to mention. Because of the cross-sectional design of the study, causality between life stressors and QoL cannot be inferred. All information in the present study was self-reported by participants which may lead to misclassification of study participants. As study participants were employees of the Esfahan Steel Company, caution should be taken in generalizing the findings of present study to the Iranian population. Although we used an Iranian validated version of EQ-5D and its validity has been approved previously, we obtained a low internal consistency based on Cronbach's alpha in our study sample, accordingly it is suggested to evaluate the validity and reliability of this instrument in a workforce population.

\section{Conclusion}

We found significant negative association between life stressors and QoL of employees. Personal stressors were more strongly associated with poor QoL than socioeconomic stressors. Proper management of stressors is required to reduce their potential adverse effects on QoL. Managing the stressors and educating stress-coping styles can play an effective role in improving QoL of employees and it could be finally effective on promoting organizational performance and job productivity.

\section{Acknowledgments}

This current study is a part of a Biostatistics PhD thesis at the School of Health, Isfahan University of Medical Sciences, with project number 395482. It was supported financially in part by Vice Chancellery for Research and Technology of University of Medical Sciences. The authors would like to express many thanks to all employees of Esfahan Steel Company who collaborated in this research.

\section{Funding}

This study was funded partially by Isfahan University of Medical Sciences (IUMS).

\section{Disclosure}

The authors report no conflicts of interest in this work.

\section{References}

1. Panzini RG, Mosqueiro BP, Zimpel RR, Bandeira DR, Rocha NS, Fleck MP. Quality-of-life and spirituality. Int Rev Psychiatry. 2017;29(3):263-282. doi:10.1080/09540261.2017.1285553

2. Karimi M, Brazier J. Health, health-related quality of life, and quality of life: what is the difference? Pharmacoeconomics. 2016;34(7):645649. doi:10.1007/s40273-016-0389-9

3. Seo EJ, Ahn J-A, Hayman LL, Kim C-J. The association between perceived stress and quality of life in university students: the parallel mediating role of depressive symptoms and health-promoting behaviors. Asian Nurs Res (Korean Soc Nurs Sci). 2018;12(3):190-196. doi:10.1016/j.anr.2018.08.001

4. Granado de la Orden S, Serrano Zarceño C, Belmonte CS. Quality of life, dependency and mental health scales of interest to nutritional studies in the population. Nutr Hosp. 2015;31(3):152.

5. Pocnet C, Antonietti J-P, Strippoli M-PF, Glaus J, Preisig M, Rossier J. Individuals' quality of life linked to major life events, perceived social support, and personality traits. Qual Life Res. 2016;25(11):2897-2908. doi:10.1007/s11136-016-1296-4 
6. Group W. The World Health Organization quality of life assessment (WHOQOL): position paper from the World Health Organization. Soc Sci Med. 1995;41(10):1403-1409.

7. Lamers LM, Meerding W-J, Severens JL, Brouwer WBF. The relationship between productivity and health-related quality of life: an empirical exploration in persons with low back pain. Qual Life Res. 2005;14(3):805-813. doi:10.1007/s11136-004-0800-4

8. Kabir-Mokamelkhah E, Bahrami-Ahmadi A, Aghili N. Work-related stress and quality of life among Iranian blue-collar workers with selfreported low back pain. Med J Islam Repub Iran. 2016;30:474.

9. Brouwer WBF, Meerding W-J, Lamers LM, Severens JL. The relationship between productivity and health-related QOL. Pharmacoeconomics. 2005;23(3):209-218. doi:10.2165/00019053-200523030-00002

10. Elizur D, Shye S. Quality of work life and its relation to quality of life. Appl Psychol. 1990;39(3):275-291. doi:10.1111/j.1464-0597.1990.tb01054.x

11. Rubel MRB, Kee DMH. Quality of work life and employee performance: antecedent and outcome of job satisfaction in Partial Least Square (PLS). World Appl Sci J. 2014;31(4):456-467.

12. Rusli BN, Edimansyah BA, Naing L. Working conditions, self-perceived stress, anxiety, depression and quality of life: a structural equation modelling approach. BMC Public Health. 2008;8(1):48. doi:10.1186/1471-2458-8-48

13. Zatzick DF, Marmar CR, Weiss DS, et al. Posttraumatic stress disorder and functioning and quality of life outcomes in a nationally representative sample of male Vietnam veterans. Am J Psychiatry. 1997;154(12):1690-1695. doi:10.1176/ajp.154.12.1690

14. Aidoo AW. The influence of stress on the health of workers in manufacturing industry. Inq J Soc Sci. 2016;2(2):65-75.

15. Clark MM, Warren BA, Hagen PT, et al. Stress level, health behaviors, and quality of life in employees joining a wellness center. Am J Heal Promot. 2011;26(1):21-25. doi:10.4278/ajhp.090821-QUAN-272

16. Piazza JR, Charles ST, Sliwinski MJ, Mogle J, Almeida DM. Affective reactivity to daily stressors and long-term risk of reporting a chronic physical health condition. Ann Behav Med. 2012;45 (1):110-120. doi:10.1007/s12160-012-9423-0

17. Charles ST, Piazza JR, Mogle J, Sliwinski MJ, Almeida DM. The wear and tear of daily stressors on mental health. Psychol Sci. 2013;24(5):733-741. doi:10.1177/0956797612462222

18. Han H-R, Kim MT, Rose L, Dennison C, Bone L, Hill MN. Effects of stressful life events in young Black men with high blood pressure. Ethn Dis. 2006;16(1):64.

19. de Paula Couto MCP, Koller SH, Novo R. Stressful life events and psychological well-being in a Brazilian sample of older persons: the role of resilience. Ageing Int. 2011;36(4):492-505. doi:10.1007/ s12126-011-9123-2

20. de Frias CM, Whyne E. Stress on health-related quality of life in older adults: the protective nature of mindfulness. Aging Ment Health. 2015;19(3):201-206. doi:10.1080/13607863.2014.924090

21. Smith SM, Vale WW. The role of the hypothalamic-pituitary-adrenal axis in neuroendocrine responses to stress. Dialogues Clin Neurosci. 2006;8(4):383.

22. Al-Ayadhi LY. Neurohormonal changes in medical students during academic stress. Ann Saudi Med. 2005;25(1):36-40. doi:10.5144/ 0256-4947.2005.36

23. Tosevski DL, Milovancevic MP. Stressful life events and physical health. Curr Opin Psychiatry. 2006;19(2):184-189. doi:10.1097/01. yco.0000214346.44625.57

24. Seib C, Whiteside E, Humphreys J, et al. A longitudinal study of the impact of chronic psychological stress on health-related quality of life and clinical biomarkers: protocol for the Australian Healthy Aging of Women Study. BMC Public Health. 2014;14(1):9. doi:10.1186/1471-2458-14-9

25. Bahri N, Najafi TF, Shandiz FH, Tohidinik HR, Khajavi A. The relation between stressful life events and breast cancer: a systematic review and meta-analysis of cohort studies. Breast Cancer Res Treat. 2019;1-9.
26. Renzaho AMN, Houng B, Oldroyd J, Nicholson JM, D’Esposito F, Oldenburg B. Stressful life events and the onset of chronic diseases among Australian adults: findings from a longitudinal survey. Eur $J$ Public Health. 2014;24(1):57-62. doi:10.1093/eurpub/ckt007

27. Rutters F, Pilz S, Koopman ADM, et al. Stressful life events and incident metabolic syndrome: the Hoorn study. Stress. 2015;18 (5):507-513. doi:10.3109/10253890.2015.1064891

28. Slopen N, Williams DR, Fitzmaurice GM, Gilman SE. Sex, stressful life events, and adult onset depression and alcohol dependence: are men and women equally vulnerable? Soc Sci Med. 2011;73(4):615622. doi:10.1016/j.socscimed.2011.06.022

29. Bhagat RS. Effects of stressful life events on individual performance effectiveness and work adjustment processes within organizational settings: A research model. Acad Manag Rev. 1983;8(4):660-671. doi:10.5465/amr.1983.4284672

30. Lu Y, Nyunt MSZ, Gwee X, et al. Life event stress and chronic obstructive pulmonary disease (COPD): associations with mental well-being and quality of life in a population-based study. $B M J$ Open. 2012;2(6):e001674. doi:10.1136/bmjopen-2012-001674

31. Staniute M, Brozaitiene J, Bunevicius R. Effects of social support and stressful life events on health-related quality of life in coronary artery disease patients. J Cardiovasc Nurs. 2013;28(1):83-89. doi:10.1097/JCN.0b013e318233e69d

32. Golden-Kreutz DM, Thornton LM, Gregorio W-D, et al. Traumatic stress, perceived global stress, and life events: prospectively predicting quality of life in breast cancer patients. Heal Psychol. 2005;24 (3):288. doi:10.1037/0278-6133.24.3.288

33. Dorji N, Dunne MP, Seib C, Deb S. Quality of life among senior citizens in bhutan: associations with adverse life experiences, chronic diseases, spirituality, and social connectedness. Asia Pacific J Public Heal. 2017;29(1):35-46. doi:10.1177/1010539516685609

34. Cleland C, Kearns A, Tannahill C, Ellaway A. The impact of life events on adult physical and mental health and well-being: longitudinal analysis using the GoWell health and well-being survey. BMC Res Notes. 2016;9(1):470. doi:10.1186/s13104-016-2278-x

35. Babu GR, Sudhir PM, Mahapatra T, et al. Association of quality of life and job stress in occupational workforce of India: findings from a cross-sectional study on software professionals. Indian J Occup Environ Med. 2016;20(2):109. doi:10.4103/0019-5278.197544

36. La Torre G, Sestili C, Mannocci A, et al. Association between work related stress and health related quality of life: the impact of sociodemographic variables. A cross sectional study in a region of central Italy. Int J Environ Res Public Health. 2018;15(1):159. doi:10.3390/ ijerph15010159

37. Lu Y-K, Qiao Y-M, Liang X, et al. Reciprocal relationship between psychosocial work stress and quality of life: the role of gender and education from the longitudinal study of the Survey of Health, Ageing and Retirement in Europe. BMJ Open. 2019;9(6):e027051. doi:10.1136/bmjopen-2018-027051

38. Ahmad M, Maon SN, Aziz NISA The relationship between job stress and quality of life among working adults. In: Proceedings of the 2 nd Advances in Business Research International Conference. Springer; 2018 261-270.

39. Collins LM, Lanza ST. Latent Class and Latent Transition Analysis: With Applications in the Social, Behavioral, and Health Sciences. Vol. 718. John Wiley \& Sons; 2009.

40. Roohafza H, Feizi A, Tirani SA, et al. Epidemiological survey of chronic diseases on manufacturing employees (ESCOME): design and methodology of a large cross-sectional study. Clin Epidemiol Glob Heal. 2019;8:257.

41. Yazdi M, Roohafza H, Feizi A, Rabiei K, Sarafzadegan N. The influence of dietary patterns and stressful life events on psychological problems in a large sample of Iranian industrial employees: structural equations modeling approach. J Affect Disord. 2018;236:140-148. doi:10.1016/j.jad.2018.04.120 
42. Association GA of the WM. World Medical Association Declaration of Helsinki: ethical principles for medical research involving human subjects. J Am Coll Dent. 2014;81(3):14.

43. Rabin R, Charro F. EQ-SD: a measure of health status from the EuroQol Group. Ann Med. 2001;33(5):337-343. doi:10.3109/ 07853890109002087

44. Group TE. EuroQol-a new facility for the measurement of healthrelated quality of life. Health Policy (New York). 1990;16(3):199208. doi:10.1016/0168-8510(90)90421-9

45. Goudarzi R, Zeraati H, Sari AA, Rashidian A, Mohammad K. Population-based preference weights for the EQ-5D health states using the visual analogue scale (VAS) in Iran. Iran Red Crescent Med J. 2016;18:2. doi:10.5812/ircmj.21584

46. Karyani AK, Rashidian A, Sefiddashti SE, Sari AA. Self-reported health-related quality of life (HRQoL) and factors affecting HRQoL among individuals with health insurance in Iran. Epidemiol Health. $2016 ; 38$.

47. Dastourani A, Mansour Sohani S, Shah Ali S. Reliability and validity of the Persian version of the european quality of life questionnaire (EQ-5D-3L) in patients with meniscus and knee ligaments injury. $J$ Paramed Sci Rehabil. 2018;7(4):73-82.

48. Roohafza H, Ramezani M, Sadeghi M, Shahnam M, Zolfagari B, Sarafzadegan N. Development and validation of the stressful life event questionnaire. Int $J$ Public Health. 2011;56(4):441-448. doi:10.1007/s00038-011-0232-1

49. Moghaddam MHB, Aghdam FB, Jafarabadi MA, Allahverdipour H, Nikookheslat SD, Safarpour S. The Iranian Version of International Physical Activity Questionnaire (IPAQ) in Iran: content and construct validity, factor structure, internal consistency and stability. World Appl Sci. 2012;18(8):1073-1080.

50. Asparouhov T, Muthen B. Multilevel mixture models. Adv Latent Var Mix Model. 2008;27-51.

51. Vermunt JK. 7. Multilevel Latent Class Models. Sociol Methodol. 2003;33(1):213-239. doi:10.1111/j.0081-1750.2003.t01-1-00131.x

52. Vermunt JK. Latent class and finite mixture models for multilevel data sets. Stat Methods Med Res. 2008;17(1):33-51. doi:10.1177/ 0962280207081238

53. Schwarz G. Estimating the dimension of a model. Ann Stat. 1978;6 (2):461-464. doi:10.1214/aos/1176344136

54. Muthén LK, Muthén B. Mplus user's guide. Version. 2018;8:2017.

55. Yazdi M, Roohafza H, Feizi A, Sarafzadegan N. Association of stressful life events and psychological problems profile: results from a large-scale cross-sectional study among Iranian industrial employees using Bayesian quantile structural equation model. EXCLI J. 2018;17:620.
56. Damush T, Hays RD, DiMatteo MR. Stressful life events and healthrelated quality of life in college students. J Coll Stud Dev. 1997;38 (January 2017):181-190.

57. Cherkil S, Gardens SJ, Deepak KS. Perceived Stressors as Determinants of Quality of Life among the Undergraduates in Medical Education. 2019.

58. Villalonga-Olives E, Rojas-Farreras S, Vilagut G, et al. Impact of recent life events on the health related quality of life of adolescents and youths: the role of gender and life events typologies in a followup study. Health Qual Life Outcomes. 2010;8(1):71. doi:10.1186/ 1477-7525-8-71

59. Ferreira C, Barreto M, Oliveira S. The link between major life events and quality of life: the role of compassionate abilities. Community Ment Health J. 2020. doi:10.1007/s10597-020-00638-z

60. Zautra AJ, Reich JW. Life events and perceptions of life quality: developments in a two-factor approach. J Community Psychol. 1983;11(2):121-132. doi:10.1002/1520-6629(198304)11:2<121:: AID-JCOP2290110206>3.0.CO;2-V

61. Coker TR, Elliott MN, Wallander JL, et al. Association of family stressful life-change events and health-related quality of life in fifthgrade children. Arch Pediatr Adolesc Med. 2011;165(4):354-359. doi:10.1001/archpediatrics.2011.13

62. Donovan O, Doody O, Lyons R. The effect of stress on health and its implications for nursing. $B r \quad J$ Nurs. 2013;22(16):969-973. doi:10.12968/bjon.2013.22.16.969

63. Seib C, Whiteside E, Lee K, et al. Stress, lifestyle, and quality of life in midlife and older Australian women: results from the stress and the health of women study. Womens Heal Issues. 2014;24(1):e43-e52. doi:10.1016/j.whi.2013.11.004

64. Cohen S, Janicki-Deverts D, Miller GE. Psychological stress and disease. JAMA. 2007;298(14):1685-1687. doi:10.1001/jama.298.14.1685

65. Michalos AC, Zumbo BD, Hubley A. Health and the Quality of Life. Soc Indic Res. 2000;51(3):245-286. doi:10.1023/A:1007010401301

66. Noone PA. The Holmes-Rahe Stress Inventory. Occup Med (Chic Ill). 2017;67(7):581-582. doi:10.1093/occmed/kqx099
Risk Management and Healthcare Policy

\section{Publish your work in this journal}

Risk Management and Healthcare Policy is an international, peerreviewed, open access journal focusing on all aspects of public health, policy, and preventative measures to promote good health and improve morbidity and mortality in the population. The journal welcomes submitted papers covering original research, basic science, clinical \& epidemiological studies, reviews and evaluations,

\section{Dovepress}

guidelines, expert opinion and commentary, case reports and extended reports. The manuscript management system is completely online and includes a very quick and fair peer-review system, which is all easy to use. Visit http://www.dovepress.com/testimonials.php to read real quotes from published authors. 